\title{
ATIVISMO EM REDE E PEDAGOGIA DECOLONIAL ARTICULADOS POR MULHERES NEGRAS NO YOUTUBE
}

\author{
Tatiana Santos da Paz \\ Eduardo Santos Junqueira Rodrigues ${ }^{1 *}$
}

\section{INTRODUÇÃO}

Este trabalho apresenta resultados parciais de estudo de tese de doutoramento sobre a experiência de três mulheres negras no YouTube com a articulação de uma pedagogia decolonial por meio da formulação de práticas ativistas em rede centradas na discussão acerca das identidades estéticas de mulheres negras. Buscou-se a compreensão sobre como estes processos assumem especificidades advindas das trocas de saberes possibilitadas pelo digital em rede e das próprias questões raciais que estruturam as narrativas produzidas por estas mulheres negras.

Para isso, partimos da discussão acerca dos campos conceituais da pedagogia decolonial e do ativismo em rede, refletimos sobre as apropriações políticas do ciberespaço como fluxos de saberes que compõem os processos formativos em rede, e buscamos tensionar esses campos a partir das questões raciais que atingem as participantes da pesquisa e mobilizam a produção de narrativas audiovisuais na plataforma comercial YouTube. Desta maneira, este artigo tem como objetivo principal demonstrar como o ativismo em rede de mulheres negras no YouTube esteve associado a uma pedagogia decolonial.

Neste trabalho, compreendemos como autorias ativistas em rede as narrativas produzidas por diferentes sujeitos que se apropriam das tecnologias sociais do seu tempo (oralidade, escrita, música, imprensa, tecnologias digitais, etc.) para manifestação de um olhar interpretativo sobre o mundo que demarca posicionamentos políticos de diferentes ordens. As autorias ativistas em rede articulam linguagens, pessoas e os saberes historicamente produzidos pela humanidade para construir um discurso próprio localizado politicamente no mundo.

\footnotetext{
(*) Tatiana S. Paz. Doutoranda em Educação Brasileira pela Universidade Federal do Ceará. Mestre em Educação e Contemporaneidade (PPGEduC/UNEB). Graduada em Pedagogia pela Universidade do Estado da Bahia. Atua como Professora no Instituto Federal do Ceará e é Pesquisadora integrante do Grupo de Pesquisa Linguagens e Educação em Rede (LER). Ordic: <https://orcid.org/0000-0001-8393-9512>.

Eduardo S. Rodrigues. Doutor em Educação pela Michigan State University, Professor Associado do Instituto UFC Virtual e professor credenciado do Programa de Pós-Graduação em Educação Brasileira da Universidade Federal do Ceará. Orcid: <https://orcid.org/0000-0001-7961-5574>.
} 
Essas narrativas construídas em rede envolvem o saber, a identidade e a racionalidade com as quais as pessoas constroem o conhecimento sobre o mundo que as cerca. Através da interlocução com outras pessoas, constroem uma compreensão de si mesmos. As mídias se constituem enquanto espaço para trocas comunicativas que possibilitam um partilhar dos dilemas sociais e principalmente de ideias propositivas para superação dos mesmos.

Apesar de todo processo de democratização da autoria apontado por autores como Levy (1999) Lemos (2010), Martins (2014), possibilitada inclusive pelos fluxos comunicacionais da cibercultura, é notável uma histórica invisibilização das autorias de mulheres negras na literatura, no jornalismo, na academia, na ciência, na música, nas telenovelas, filmes, etc., que se perpetua na contemporaneidade. No entanto, muitas mulheres negras protagonizaram e protagonizam a produção do discurso e constituem suas autorias desde o período colonial no Brasil.

Apesar disso, no contexto contemporâneo, com o advento das tecnologias digitais em rede, os processos autorais de mulheres negras se atualizaram e se ampliaram através da escrita (blogs, redes sociais, etc.), da oralidade (podcasts, músicas, etc.) ou do audiovisual (clipes, vídeos, curtas, filmes, etc.) que circulam nas redes. Neste contexto de apropriação política do ciberespaço, situamos a prática autoral e ativista de três vlogueiras acerca da identidade estética da mulher negra.

\section{ATIVISMO EM REDE}

A emergência de modos de comunicação pós-massivos provocados pelas mudanças culturais na cibercultura proporcionaram meios para que se tornasse possível novas maneiras de agir politicamente, ainda que muitas vezes com um índice de intencionalidade conscientizada menor. Ao fazer isso, a cibercultura produz uma mudança significativa na forma como nos relacionamos cotidianamente com a esfera política (JUNGBLUT, 2015).

Para Haraway (2009), o olhar sobre este contexto deve considerar as ambiguidades desse processo. Segundo ela, a tecnologia contemporânea serve tanto às empresas de controle e exploração situadas nos sistemas de poder vigentes, como também pode nos ajudar a transformar em sentido libertário nossas experiências com nossa cultura, nosso trabalho, nosso modo de vida, nossas relações sociais e nossas identidades individuais. Esse olhar está em sintonia com o conceito articulado por Rudiger (2003) para quem “a cibercultura é o movimento histórico, a conexão dialética, entre o sujeito humano e suas expressões tecnológicas, através da qual transformamos o mundo e, assim, nosso próprio modo de ser interior e material em dada direção (cibernética)" (p. $54)$. 
Para Castells (2013), a Internet tem se tornado um novo cenário de mobilizações, denúncias, debates que revelam um movimento de apropriação das redes como mais um espaço de atuação política. Di Felice (2013), no entanto, compreende que, com as articulações de ações ativistas no ciberespaço, não houve só uma mudança de cenário, pois as tecnologias proporcionaram uma transformação nas próprias práticas. Para ele, “o que constitui a característica própria do ciberativismo, ou ativismo online, [...] inclui a forma como essa tecnologia comunicativa transformou substancialmente o próprio ativismo e os conceitos de participação, espaço democrático, identidade coletiva e estratégia política" (p. 54) através do ato conectivo entre os participantes do ativismo nas redes digitais.

As diferentes plataformas de interação social disponíveis no ciberespaço oferecem soluções para a manifestação de afinidades, simpatias, concordâncias, engajamentos, antipatia, discordância, etc. As pessoas compõem o quadro de informações que estruturam seus "perfis", associando-se a comunidades, causas, ideais políticos que agreguem valores àquela forma de existência naquelas plataformas. Nesses espaços, é possível manifestar posicionamentos políticos através de funcionalidades como as do botão "like" ou "curtir" em sites como Facebook (JUNGBLUT, 2015).

No caso do YouTube, plataforma comercial onde são compartilhados os vídeos das três mulheres negras participantes da pesquisa, o modelo de negócios assumido pela Google se baseou em uma fusão entre estratégias online inovadoras e as táticas midiáticas convencionais. Uma delas é a forma como o algoritmo da plataforma trabalha. Enquanto os usuários acreditam que possuem total controle sobre o que estão assistindo, eles estão sendo influenciados a assistirem a determinados conteúdos sugeridos pela plataforma, assim como na dinâmica da televisão. No YouTube, este controle é gerenciado através do ranqueamento dos vídeos, sua popularidade, dentre outros fatores operados pelo modelo de negócios da plataforma (VAN DIJCK, 2016).

Van Dijck (2016), em seu estudo acerca das plataformas, discute como a mídia conectiva avança a cada dia e codifica as conexões humanas como dados e os convertem em bens que produzem valor. Esta dinâmica provoca uma nova socialidade online da qual ainda desconhecemos os vetores de sua governança. Ou seja, não sabemos, segundo a autora, como as nossas interações continuarão se movendo e serão governadas.

Nessa perspectiva, o nosso olhar para as práticas ativistas em rede, articuladas pelas vlogueiras no contexto da cibercultura, compreende que o próprio ativismo articulado por essas mulheres negras será envolvido pelas nuances próprias do funcionamento da plataforma e do seu modelo de negócios. Assumimos, assim, a premissa de que "a técnica não é em si mesma boa ou 
má, porque isso depende dos seus usos e contexto, e tampouco neutra, porque é condicionante ou restritiva: de um lado abre e de outro fecha as possibilidades de intervenção humana" (RUDIGER, 2003, p. 63). Além disso, compreendemos que estas especificidades que envolvem as ações ativistas de mulheres negras no YouTube são parte dos processos formativos experimentados por elas na construção e distribuição das narrativas audiovisuais.

Esta rede colaborativa proporcionada pelas tecnologias digitais coloca em cena novos mediadores e produtores de narrativas que surgem como um discurso político "fora de lugar" que não tem origem na universidade, no Estado, na mídia tradicional, ou em um partido político, mas na voz de indivíduos que passam de "objetos" a sujeitos do discurso. Estes contribuem com uma renovação do político, e com os discursos mais contundentes sobre racismo, violência policial, pobreza e concorrem com os discursos da universidade e da mídia (BENTES, 2009).

A produção dessas narrativas acontece muitas vezes em dinâmicas que estão distantes dos espaços formais de ensino, o que nos faz refletir, neste trabalho, sobre como compreendemos a ideia de formação e como os praticantes culturais estão instituindo seus próprios processos de interpretação sobre o mundo que os cerca e mobilizando saberes circulantes em rede. Frequentemente, agregamos ao significado de formação uma ação ou atividade que ocorre nas instituições de ensino. Ainda que esta perspectiva de formação seja importante e válida no campo da educação, o caráter das experiências analisadas de mulheres negras no YouTube nos conduz a um olhar sobre os processos formativos que não se restringe aos âmbitos formais de aprendizagem, mas que são constituídos no fluxo das experiências cotidianas (JOSSO, 2002).

Essas experiências formativas estão em sintonia com a ideia da pedagogia decolonial proposta por Walsh (2008) por meio do diálogo entre os estudos de Paulo Freire e Frantz Fanon. A pedagogia decolonial vai além das práticas de transmissão do conhecimento e compreende ações articuladas em escolas, universidades, bairros, movimentos e nas ruas que integram o questionamento e a análise críticas acerca das práticas sociais centradas na colonialidade, ainda presentes nos livros didáticos, na auto-imagem dos povos subalternizados, na cultura, etc.

A colonialidade do poder reprime os modos de produção de conhecimento, os saberes e as imagens do colonizado e impõe novos invisibilizando-o e subalternizando-o (QUIJANO, 2005). Já a decolonialidade parte da desumanização e das lutas dos povos historicamente subalternizados pela existência, para a construção de outros modos de viver, de poder e de saber ao visibilizar as lutas contra a colonialidade a partir das pessoas, das suas práticas sociais, epistêmicas e políticas. 
A pedagogia decolonial, para Walsh (2008), portanto, se constitui por meio de uma prática sociopolítica produtiva e transformativa baseada nas realidades, subjetividades, histórias e lutas das pessoas, que são vivenciadas em um mundo regido por uma estrutura colonial. Nesse sentido, situamos as experiências de três mulheres negras no YouTube que ampliam as possibilidades de construção de novas narrativas sobre as identidades de mulheres negras, sobre as quais ainda persiste um olhar colonial na contemporaneidade.

\section{Metodologia}

Esta pesquisa possuiu uma abordagem qualitativa (BOGDAN; BIKLEN, 1994) e teve como principais técnicas a entrevista semiestruturada e observação participante. O objetivo principal da pesquisa foi compreender como as ações em rede de mulheres negras no YouTube articulam um novo ativismo e processos formativos decoloniais. Para isso, foram analisados eventos (vídeos e suas repercussões em rede) referentes aos canais de cada vlogueira - Luciellen Assis, 11 vídeos; Ana Paula Xongani, 12 vídeos; Gabi Oliveira, 15 vídeos. Os eventos correspondem às postagens de vídeos realizadas pelas vlogueiras, ou seja, foram analisadas as trocas em rede articuladas em torno das suas publicações. A coleta de dados se deu através da realização de entrevistas semiestruturadas com as mesmas e da observação das atividades ocorridas nos canais em períodos que, ao longo de três anos, totalizaram 12 meses.

O critério utilizado para a escolha dos vídeos teve como base os conteúdos articulados com o ativismo das mulheres negras participantes da pesquisa no YouTube. Foram selecionados, em cada canal, vídeos que representassem as diferentes temáticas discutidas dentro do eixo relações étnico-raciais e que evidenciassem a diversidade de abordagens que caracterizavam as narrativas construídas. A observação participante foi realizada no ambiente online YouTube, onde a pesquisadora acompanhou as postagens e comentários feitos nos eventos selecionados e registrou, em um diário de campo, as ocorrências dos eventos.

Os eventos foram selecionados com base nos seguintes critérios: alinhamento aos objetivos e temática do estudo proposto; indicação de importância do vídeo publicado segundo critérios das próprias vlogueiras tendo em vista os objetivos delas com o canal que gerenciam; as repercussões quantitativas (número de acessos e de comentários a um vídeo específico no canal) e qualitativas (uma interação distinta observada entre vlogueira e usuários no canal, uma temática central para a vlogueira, dentre outros).

Os resultados da pesquisa, aqui apresentados, foram desenvolvidos a partir das análises sobre os eventos selecionados durante o período de observação participante nos três canais do 
YouTube que constituíram o campo digital do estudo: Ana Paula Xongani, Gabi DePretas e Luciellen Assis. As informações relatadas na pesquisa agregaram os eventos observados no YouTube, bem como o discurso das vlogueiras coletados através das entrevistas semiestruturadas. O dataset do estudo foi formado pelos conteúdos dos vídeos publicados nos canais do YouTube, as interações entre vlogueiras e interatores nos respectivos canais da interface digital observada, os conteúdos de entrevistas semiestruturadas realizadas com as três vlogueiras durante o trabalho de campo e trechos do diário de campo relacionados aos eventos selecionados.

\section{MULHERES NEGRAS E ATIVISMO EM REDE}

As ações em rede protagonizadas pelas vlogueiras se iniciaram em torno da questão do cabelo crespo e se ampliaram para outras questões que envolvem a identidade estética da mulher negra. Observou-se que as narrativas construídas e compartilhadas por essas mulheres negras possuíam um caráter político no que se refere às disputas de narrativas com a mídia tradicional acerca da identidade estética da mulher negra.

Do ponto de vista do conteúdo, observou-se que os fragmentos das histórias de vida dessas mulheres constituíram-se como elementos centrais das narrativas, através das quais as mesmas elaboraram interpretações e leituras críticas de fatos do cotidiano, especialmente aqueles que tratavam de questões raciais; percebeu-se, ainda, que o tema central das discussões nos vídeos era "identidades estéticas das mulheres negras"; e que as narrativas possuíam um caráter ativista ao tratar das questões de gênero e raça nos canais.

As experiências com o cabelo possuíam uma centralidade nos vídeos inaugurais do canal de Gabi Oliveira e de Luciellen Assis. Ambas relatavam suas experiências negativas na infância e positivas durante processo de transição capilar. $\mathrm{O}$ olhar negativo sobre o cabelo foi algo comum na trajetória das duas vlogueiras, principalmente durante a infância. Para elas, a experiência com a mídia através da falta de representatividade de mulheres negras com cabelo crespo, bem como as vivências na escola, contribuíram para um olhar inferiorizado sobre si. Como um artifício de conexão entre as suas histórias de vida e das suas seguidoras, elas também mostravam fotos do processo de transição capilar e sugeriam às suas interlocutoras que buscassem um olhar positivo sobre si mesmas, subvertendo as narrativas construídas pela mídia. 
Imagem 1. Imagens do processo de transição de Luciellen Asssis

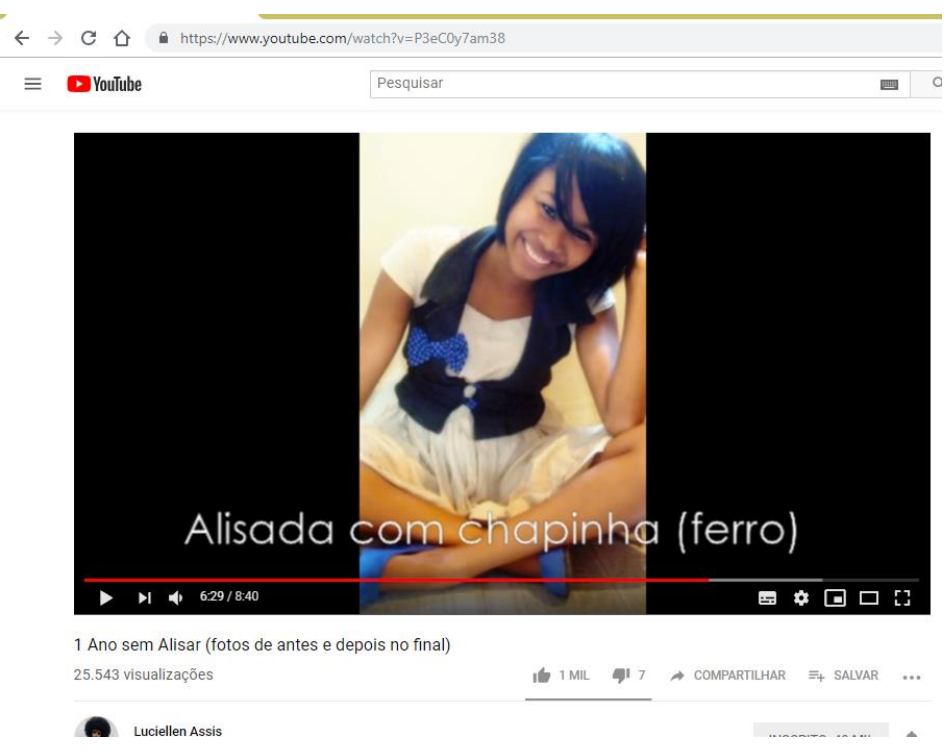

Fonte própria.

Percebeu-se também que o racismo estrutural (ALMEIDA, 2018) demonstrado pela pouca representatividade do cabelo crespo natural nos conteúdos publicitários, cinematográficos, e dramatúrgicos, foi combatido por essas mulheres negras quando decidiram questionar a mídia e as grandes empresas de cosméticos que atuavam como reprodutoras dos processos de marginalização da estética negra. Nesse sentido, as possibilidades comunicacionais das mídias de função pósmassiva (LEMOS, 2010) permitiram a articulação de trocas comunicacionais em espaços como o YouTube, que possibilitaram a criação de novas narrativas sobre o cabelo crespo e as identidades estéticas das mulheres negras, que disputavam com o discurso das mídias tradicionais.

O conteúdo dessas narrativas foi construído em diálogo com os internautas, que ampliaram o espectro dos conteúdos dos vídeos ao construírem seus olhares divergentes, contraditórios e complementares através dos comentários. No vídeo "Preto é tudo ladrão?", por exemplo, Luciellen Assis discutiu os estereótipos associados a pessoas negras e foram publicados comentários que reforçavam seu discurso com exemplos do cotidiano, com acréscimos de informações ou análises sobre o caso, elogios ao conteúdo do vídeo, bem como análises que relacionavam o fato avaliado pela vlogueira com a situação de corrupção no Brasil. O internauta Jo play indicou com o seu comentário que o estereótipo associado ao homem negro mencionado no vídeo - ladrão - não condizia com as práticas estruturais de corrupção no país, o que demonstrava, para ele, a construção de um estereótipo racista. 
Imagem 2: comentário sobre o vídeo "Preto é tudo ladrão?"

Jo play 1 ano atrás

O NEGRO É TÃO LADRÃO QUE O BRASIL FOI TODO SAQUEADO, MAS ADIVINHA QUEM FOI QUE ROUBOU ?, Á COMEÇAR PELO OS POLÍTICOS DO NOSSO PAIS QUE É 99\% BRANCOS, AS EMPRESAS MAIS CORRUPTAS DO NOSSO PAÍS ADIVINHA QUEM ADMINISTRA, BRANCOS, ELES DENTEM EM MÃOS TODA NOSSAS RIQUEZAS E TOTALMENTE ILICITA E ASSIM POR DIANTE. TA NA HORA DA GENTE COMEÇAR A DESCONSTRUIR ESSA FALA DE BRANCOS OPRESSORES.

It 3 \& 8 RESPONDER

Fonte: própria

Havia também nas falas das vlogueiras um constante convite ao diálogo ou à ação de combate ao racismo. Em um de seus vídeos, Gabi Oliveira se questionou sobre o que as mulheres negras faziam contra a perpetuação do racismo estético expresso cotidianamente pela forma como as pessoas negras eram representadas na mídia.

Nós vivemos num país profundamente afetado pelo racismo, onde isso [foto de mulher branca], isso [foto de mulher negra de pele clara] é até aceitável, e isso daqui [foto de mulher negra retinta] é horrível, feio. Mas essas referências do que é bonito e do que é feio não nascem com a gente e nós podemos sim questioná-las e parar de reforçá-las. [...] E um questionamento que surge pra mim é: o que nós temos feito pra que o racismo estético não se perpetue? (Transcrição de trecho de Oliveira, 2018)

O fazer comunicacional dessas mulheres possuía um caráter ativista, expresso na disputa pela construção de novas narrativas em rede sobre a estética negra. Gabi Oliveira, por exemplo, expôs no trecho de um dos seus vídeos (Tour pelo meu corpo) como a marginalização dessa estética atinge as pessoas negras, que são frequentemente associadas ao crime, abandono, primitivismo. Para ela, o racismo expresso nessas nuances atingiu a sua autoestima, que já demonstrava marcas de dor, mas também de aceitação, fruto de um processo de desconstrução dessas representações.

É notável que os vlogs de Gabi Oliveira e Luciellen Assis iniciaram com uma abordagem voltada para a discussão sobre autoestima, porém se tornou inevitável enfatizar o debate acerca da estética negra e associar ao contexto histórico que elucida as causas do processo de marginalização do cabelo crespo. Tais temáticas se tornaram indissociáveis na visão das vlogueiras, na medida em que perceberam o quanto o retorno ao cabelo natural causou incômodo socialmente; para elas, era fundamental compartilhar tais reflexões no YouTube. Para Gabi Oliveira, o seu canal iniciou com a ideia de dar visibilidade à discussão sobre estética negra, especialmente discussões protagonizadas por pessoas de pele retinta, como ela. 
O ativismo também se expressava nas discussões sobre o caráter político de assumir o cabelo natural que estavam presentes nas dimensões mais práticas do cotidiano como ensinar a cuidar do cabelo crespo, já que estas garotas tinham uma relação de escassez com os produtos cosméticos e com cabeleireiros, pois encontravam um número muito reduzido de produtos e serviços próprios para cabelos crespos.

Foi possível observar que os canais possuíam também um papel de tradução de conhecimentos em rede, na medida em que as autoras dos canais demonstravam interesse por compartilhar conhecimentos que muitas vezes não eram acessíveis a toda a comunidade negra. Gabi Oliveira entendia que um dos principais motivos para criação do seu canal foi a busca por difundir um conhecimento importante, segundo ela, para a população negra e pessoas que não estavam inseridas no universo acadêmico. Para ela, a apropriação destes conhecimentos é fundamental para a construção da autoestima de pessoas negras, bem como para o amadurecimento das suas lutas no que se refere ao âmbito étnico-racial. De acordo com a vlogueira,

o Canal iniciou pela necessidade que eu senti de transmitir uma mensagem que eu só conheci na universidade pra pessoas no geral assim. A gente sabe que a grande maioria da população negra nem tem acesso a esse espaço acadêmico e por isso fica muito afastada de assuntos que são muito necessários para que a gente cresça em autoestima, em luta e em entendimento também de questões raciais.

Percebeu-se, ainda, que havia, nos conteúdos de alguns vídeos publicados nos canais, a articulação de uma interface entre diferentes tipos de conhecimento como textos acadêmicos, literários ou narrativas de filme e séries associados às experiências de vida das vlogueiras. No vídeo “Tour Pelo Meu Rosto", Gabi Oliveira fez referência ao texto de Malcolm X, para discutir sobre autoestima: "E pra quem tem características como as minhas e ainda está no processo, eu deixo aqui as palavras do MalcomX: Quem te ensinou a odiar a textura do seu cabelo? Quem te ensinou a odiar a cor da sua pele ao ponto que você almeja ficar mais branco?" (Transcrição de trecho de Oliveira, 2018). ${ }^{2}$

No vídeo "Vamos ficar bem: um vídeo sobre autoestima", após falar sobre o tema, Gabi Oliveira explicou aos seus seguidores por que fez a escolha de inserir no seu discurso o conhecimento acadêmico para discutir sobre o conteúdo. "E porque eu decidi fazer esse vídeo assim ‘tão teórico' pra falar sobre algo tão simples como autoestima? Porque a gente só consegue avançar

\footnotetext{
${ }^{2}$ Trecho do vídeo Tour Pelo Meu Rosto | Papo DePretas. Disponível em: <https://www.youtube.com/watch?v= CEOvcHPvvis\&t=400s $>$.
} 
pra cura, quando a gente começa a entender a raiz do problema." (Transcrição de trecho de Oliveira, 2016)3

Segundo Santos (2017), os ativistas operam frequentemente a tradução intercultural entre o conhecimento nascido na luta e o conhecimento acadêmico, com vista a construir novas configurações cognitivas e políticas, processo designado por ele como ecologia de saberes. O conhecimento nascido na luta não avança de modo isolado, entra em diálogo com outros conhecimentos, como é possível perceber na descrição do vídeo em que Gabi Oliveira discutiu autocuidado como estratégia política através de uma relação entre diferentes fontes de conhecimento (ver Imagem 3).

Imagem 3. Caixa de descrição do Vídeo Autocuidado como estratégia política que agrega conhecimentos diversos circulantes em rede.

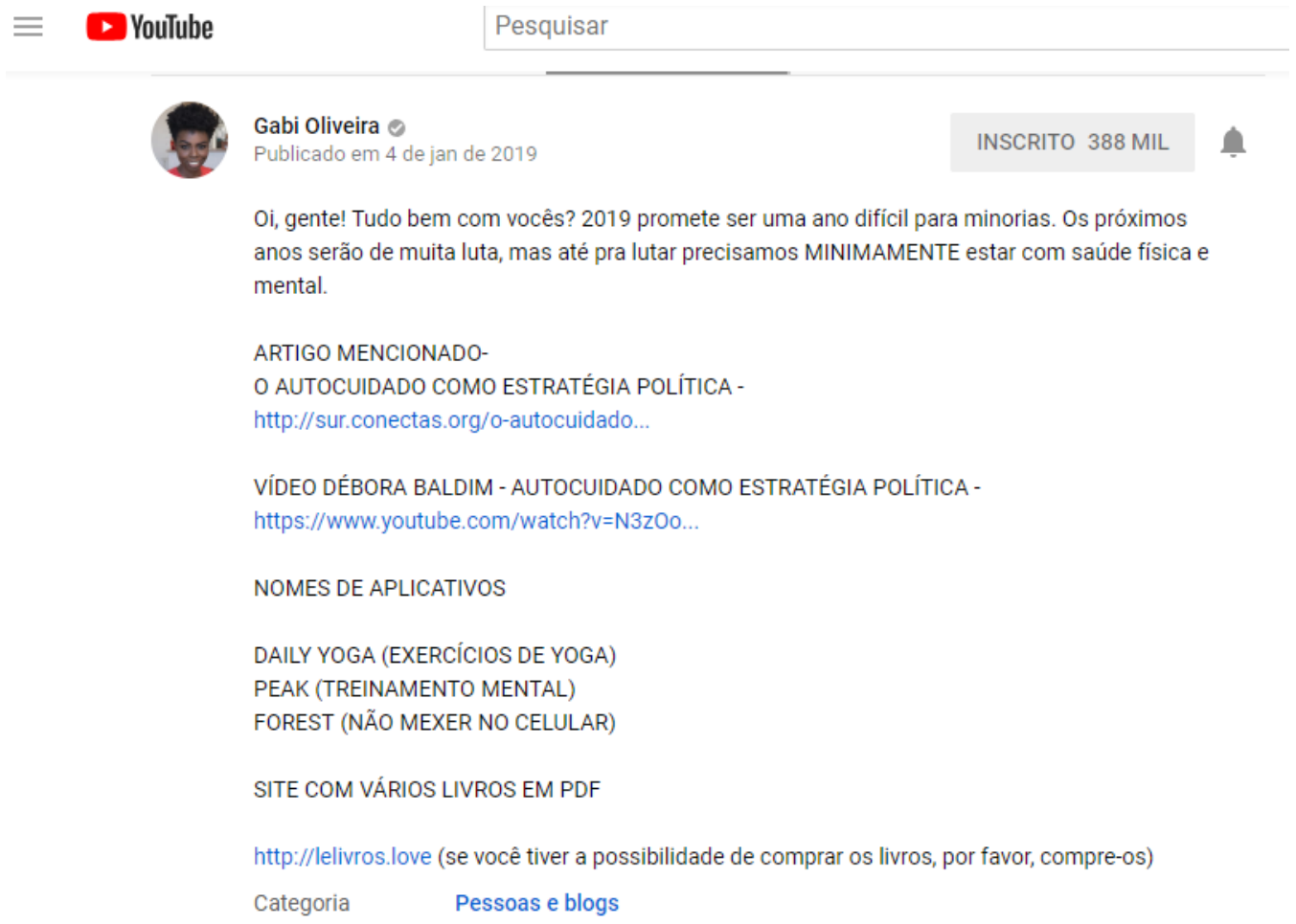

Fonte: Própria.

No vídeo, a vlogueira começou sua narrativa explicando como iniciou as reflexões sobre autocuidado como estratégia política. Gabi Oliveira mencionou conversações com seus seguidores

3 Trecho do vídeo Vamos ficar bem: um vídeo sobre autoestima | Papo DePretas de Gabi. Disponível em: https://www.youtube.com/watch?v=SQ7qTeDJCe0 
nas redes sobre o tema e afirmou que, paralelamente às trocas, ela teve acesso a um vídeo ${ }^{4}$ no YouTube em que a vlogueira Débora Baldin discutia, a partir de um texto científico, o autocuidado como uma estratégia fundamental para garantir o bem estar de ativistas defensoras de direitos humanos em lugares de alta violência contra a mulher e, consequentemente, fortalecer as suas lutas. Após ver o vídeo, ela leu o artigo ${ }^{5}$, e produziu o seu vídeo no qual citou fragmentos deste texto acadêmico e estabeleceu relações com o contexto político do país - após as eleições de 2018, em janeiro de 2019, tomou posse o candidato que proferiu antes e durante a campanha declarações ${ }^{6}$ racistas, homofóbicas, misóginas e pró-tortura. No vídeo, Gabi Oliveira sugeriu práticas que ajudassem no cuidado físico e mental e que pudesse servir como estratégia política.

Natály Neri, autora do Canal Afro e Afins, destacou o caráter ativista das narrativas audiovisuais de mulheres negras no YouTube no vídeo Tipos de militância e ativismo com Nataly Neri | DePretas ${ }^{7}$ no Canal De Pretas - Gabi Oliveira. De acordo com a vlogueira, a Internet possibilitou novas formas de ativismo que são apropriadas por mulheres negras atualmente. Para ela, esse tipo de ativismo ainda não era legitimado pelos movimentos sociais tradicionais de maneira geral, que compreendiam essa atuação de forma branda e pouco transformadora.

Geralmente as pessoas mais velhas dos movimentos sociais, isso eu não tô falando de uma maneira generalizada, julgam muito as nossas formas de lidar com as coisas, "ah é uma militância muito passiva, é uma militância muito fofa, é uma militância que só faz vídeo na internet", como se isso não fosse poderoso, como se isso não mudasse a realidades e pensamentos, como se isso não mudasse a nós mesmas, né?"(Transcrição de trecho de Neri, 2016)

De acordo com a vlogueira, existe uma diversidade de formas para os ativismos na contemporaneidade, que se tornam complementares. As várias formas de organização política possuem uma importância e podem se articular. Gabi Oliveira concordou que a construção dessas narrativas envolvia coragem para o enfrentamento do racismo. "A gente ter coragem de falar das nossas questões nunca vai ser fofinho na sociedade onde a gente vive. Não vai ser fofo, nunca é."

\footnotetext{
4 Trecho do vídeo Autocuidado como estratégia política. Disponível em: <https://www.youtube.com/watch?v= $\underline{\mathrm{N} 3 z O o 9 u d V e M}>$.

5 Texto científico: O autocuidado como estratégia política. Disponível em: <https://sur.conectas.org/o-autocuidadocomo-estrategia-politica/>. Acesso dia 18 de maio de 2019.

${ }^{6}$ Declarações podem ser acessadas em: https://bit.ly/2H786Be.

7 Trecho do vídeo "Tipos de militância e ativismo com Nataly Neri | DePretas". Disponível em: https://www.youtube.com/watch?v=yPm1nDdcq-o\&t=2s
} 
(Transcrição de trecho de Oliveira, 2016)8 Ainda que existissem questionamentos acerca do caráter ativista, essas mulheres negras jovens afirmavam o seu lugar numa militância articulada na internet como autoria de uma geração que encontrou nos sites de redes sociais e na própria estética uma nova linguagem pela qual é possível lutar contra o racismo.

A relação com as marcas de fabricantes de produtos comerciais foi outra questão observada na construção das narrativas ativistas dessas mulheres negras que, ao buscarem novas representações da identidade estética da mulher negra, questionaram o mercado sobre a representatividade de pessoas negras na publicidade, bem como na produção de produtos voltados para a pele negra e cabelo crespo - até então, pouco presentes nas prateleiras das lojas. Segundo pesquisa da Google, em 2017, a expressão "cabelos cacheados" ultrapassou pela primeira vez a busca pelos "lisos" no Google, um crescimento de $232 \%$, e o interesse por "cabelos afro" aumentou $309 \%$ nos últimos dois $\operatorname{anos}^{9}$ Para a empresa, que comercializa dados sobre o perfil de buscas nos seus sites, esse crescimento representa uma nova possibilidade de mercado para as empresas que usufruem dos dados gerados pela apropriação da plataforma por essas mulheres ativistas. Esse aumento demonstrado pelos dados produzidos pelos buscadores são vendidos para empresas que tomam esses dados como fonte de pesquisa mercadológica. Apesar de reconhecerem que seus conteúdos servem a este fim, as vlogueiras estabeleceram relações comerciais com estas marcas.

Gabi Oliveira afirmou que, ao estabelecer relações comerciais com marcas comerciais, buscou questioná-las acerca das suas contribuições efetivas para a luta antirracista, por exemplo. Segundo a vlogueira, "um dos processos que a gente faz com as marcas que procuram a gente pra um relacionamento mais longos é questionar quais os processos internos elas têm estabelecido pra que a diversidade esteja só na propaganda" (Transcrição de trecho de Oliveira, 2016) ${ }^{10}$ Nos comentários, um de seus seguidores reafirmou a compreensão de que o objetivo final das marcas, quando buscam acompanhar as demandas sociais, é simplesmente o lucro (ver Imagem 4). O seguidor dialogou com Gabi e demais seguidores do canal.

\footnotetext{
8 Trecho do vídeo Representatividade importa: Desabafo Social + DePretas + Catarse. Disponível em: https://www.youtube.com/watch?v=BNALNSBymp0\&t=2377s

${ }^{9}$ https://www.thinkwithgoogle.com/intl/pt-br/advertising-channels/v\%C3\%ADdeo/revolucao-dos-cachos/

10 Trecho do vídeo Marcas e Projetos sociais? $\mid$ DEPRETAS. Disponível em: <https://www.youtube.com/

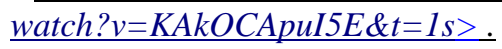


Imagem 4. Comentário sobre comprometimento das marcas com as demandas sociais

Mano irmano 3 meses atrás (editado)

Bacana hein , as marcas geralmente acompanham as demandas sociais ;as pessoas ainda não se deram conta do poder que elas tem, quando estão unidas. Quando um determinado grupo começa a ganhar um certo destaque social, o mesmo passa a ser usado como vitrine e divulgação para as marcas, que visam o lucro .Exemplo : agora esta na moda falar sobre racismo e representatividade, logo já existem mais propagandas comercias com negros de protagonistas, ainda são poucas, mas se comparar ao passado está mudando. As marcas não são bobas e já perceberam que um publico melhor informado vai buscar aquilo que os representa. 0 negro que faz essa reflexão sobre o papel das mídias na vida social das pessoas começa a buscar se vê melhor representado, e não busca mais a validação branca; mais sim a valorização da sua estética, do seu grupo social. Mostrar menos

It 9 ? RESPONDER

Fonte: própria.

As falas de vlogueiras como Ana Paula e Gabi Oliveira demonstraram que as narrativas audiovisuais construídas possuíam um viés político com foco nas opressões de gênero e raça, porém não existia uma aparente luta anticapitalista. Ana Paula Xongani, com base nas suas experiências, criou a hipótese de que há no YouTube uma política de distribuição dos vídeos que está relacionada com os interesses comerciais das marcas e que restringem a visibilidade de vídeos que não estão alinhados com as políticas das empresas, por exemplo. Não faria sentido, para ela, que uma empresa investisse em anúncios que antecedem narrativas que se contrapõem à própria empresa:

Para mim são seres humanos, cabeças pensantes, com estratégias muito bem delineadas, sabendo muito bem o que estão fazendo, utilizando da ferramenta do poder para influenciar e definir quem serão os influenciadores. E claro com o combustível mais potente do mundo que é o dinheiro. Essa mudança no algoritmo, eu tenho para mim que o que mudou são as marcas. Não dá para eu anunciar um negócio da Avon e depois vem a cara preta da Ana Paula dizendo que a Avon não tem base para o meu tom de pele. Então eles falam: "Não, vocês vão ter que fazer alguma coisa aí para eu não correr esse risco.’[Trecho de entrevista com Ana Paula Xongani]

Para Ana Paula, era notório que o YouTube reproduzia as facetas do racismo institucional e das opressões de gênero e suas dinâmicas refletiam a estrutura social. Ela contrastou sua experiência com a de vlogueiras brancas e destacou como a dimensão racial operava na visibilidade e credibilidade das narrativas construídas no YouTube. Gabi Oliveira, com o mesmo entendimento sobre a plataforma, questionou a forma como o modelo de negócios que rege a plataforma privilegiava pessoas brancas em detrimento de pessoas negras, mesmo quando estas últimas não articulavam discursos ativistas e críticos. "Porque quantas meninas [negras] têm um conteúdo muito bom, mas não conseguem desenvolver, porque não têm nenhum apoio assim, não tem nada. [...] Eu 
conheço vlogueiras negras com cem, cento e cinquenta mil inscritos que não recebem nem um terço das propostas [comerciais] que vlogueiras brancas com menos inscritos recebem” (Transcrição de trecho de Oliveira, 2016).11

A relação entre os interesses comerciais das marcas que publicam anúncios no YouTube e a distribuição dos vídeos na plataforma foi fundamental para a compreensão de como os vídeos dessas mulheres negras circulavam e como isso poderia limitar o alcance das suas narrativas políticas. $\mathrm{O}$ ativismo constituído em rede poderia sofrer barreiras no que se refere à visibilidade e distribuição dos seus discursos quando o conteúdo produzido confrontava os propósitos comerciais de empresas que financiam a plataforma.

Com todas essas nuances próprias de um ativismo articulado em rede hoje, a Internet se tornou um novo campo de disputa de narrativas políticas sobre as identidades das mulheres negras onde operam interesses diversos, dentre eles os comerciais do YouTube na experiência ativista da vlogueiras. Neste contexto, emergem as principais características do ativismo em rede protagonizado pelas vlogueiras negras:

a) Estruturado com base nas experiências das vlogueiras com o cabelo crespo natural;

b) Constituído em rede - construção das narrativas, as tensões com a plataforma YouTube e as trocas com os seguidores;

c) Formado inicialmente pela produção de vídeos com objetivos de construção de narrativa alternativa à mídia tradicional;

d) Centrado nas discussões sobre a identidade estética da mulher negra, com destaque para a discussão sobre cabelo;

e) Articulador de uma tradução de conhecimentos acadêmicos;

f) Objetiva a luta contra as opressões raciais e de gênero que atingem as mulheres negras;

g) Possui articulações com o mercado e com relações de consumo de mulheres negras;

h) Opera em tensão com mecanismos comerciais e outros do YouTube pouco transparentes.

Suas ações políticas se concentraram numa crítica à sub-representação das mulheres negras nos diferentes espaços sociais, especialmente na mídia; à forma como o racismo estrutural gera um mal estar entre mulheres negras a respeito da sua autoestima; denúncia da ausência de produtos

11 Trecho do vídeo Representatividade importa: Desabafo Social + DePretas + Catarse. Disponível em: <https://www.youtube.com/watch?v=BNALNSBymp0\&t=2377s $>$. 
estéticos para mulheres negras. Este ativismo, no entanto, operou em tensão com interesses diversos, do mercado publicitário e da plataforma YouTube, dentre outros. Nesse sentido, o discurso produzido pelas vlogueiras abrangeu as esferas de opressões relativas às questões de gênero e raça, mas não se posicionou enquanto narrativa anticapitalista. Verificou-se, dessa forma, uma estratégia que poderia tanto desmobilizar ou descaracterizar suas lutas, mas que também poderia ampliar o seu alcance ao lhes propiciar maior exposição e audiência através do aumento do alcance das suas publicações na plataforma.

O ativismo em rede articulado por estas mulheres se constituiu na forma como construíram as narrativas articulando diversos conhecimentos; nas tensões que envolviam o funcionamento dos canais na plataforma YouTube e as questões raciais presentes nos conteúdos dos seus vídeos, que constituem a pedagogia decolonial; bem como nas trocas estabelecidas com os seguidores dos canais.

\section{CONSIDERAÇÕES FINAIS}

Verificamos, portanto, que o ativismo constituído pelas narrativas audiovisuais em rede produzidas por essas mulheres tinham em comum: a) a temática central dos canais (identidade estética das mulheres negras); b) uma relação direta das narrativas com as suas histórias de vida; c) suas experiências com o racismo; d) interesse por apoiar outras mulheres negras no enfrentamento do racismo na sua vida cotidiana; e) trocas comunicacionais com seguidores do canal que ampliaram o conteúdo da narrativa, abrindo espaço para o pensamento divergente, contraditório e complementar.

A afirmação positivada dessa estética perpassa por uma luta da mulher negra que envolve a conquista de espaços de trabalho, afetivo, midiático. As ativistas mesmas lançaram mão do desenvolvimento de um olhar interpretativo sobre suas experiências cotidianas na perspectiva racial e construíram narrativas que agregavam perspectivas sobre o que é ser mulher negra no tempo presente, por vezes em diálogo com saberes acadêmicos e com seguidores do canal.

As reflexões propostas neste trabalho trouxeram contribuições para o campo da educação ao evidenciar, por meio da experiência ativista dessas mulheres, a possibilidade de articulação de saberes fundados nas histórias de vida e que circulam em rede em diálogo com outras mulheres. Mediada pelas tecnologias digitais em rede, a prática de mobilizar reflexões sobre o lugar social que ocupam como mulheres negras aproxima essas experiências às pedagogias críticas da libertação, que reconhecem as políticas de identidade como uma luta dos oprimidos para criticar as estruturas 
dominantes, perspectiva que abraça a experiência como modos de conhecimento válidos e como dimensões vitais de qualquer processo de aprendizagem (HOOKS, 2017).

É possível compreender, a partir das experiências dessas mulheres, que as suas narrativas apresentam uma busca pelo rompimento com valores que a colonialidade do poder construiu sobre a subjetividade dos subalternizados (QUIJANO, 2005). Assim, a experiência dessas três mulheres negras apontam aproximações de uma pedagogia decolonial (OLIVEIRA; CANDAU, 2010), que surge da reivindicação, pelos povos subalternizados, de novos olhares sobre si, valorização de suas epistemologias e uma descolonização de mentes, corpos e espaços e que enseja aprendizagens ao circular pelas redes digitais. 


\section{REFERÊNCIAS}

ALMEIDA, S. O que é racismo estrutural. Belo Horizonte: Letramento, 2018.

BENTES, I. Redes colaborativas e precariado produtivo. online. Revista Periferia. Rio de Janeiro v.1, n.1. p. 53-61. 2009. Disponível em: 〈http://www.e-publicacoes.uerj.br/index.php/periferia/article/view/3418>. Acesso em 10 nov. 2015.

CASTELLS, M. A sociedade em rede. São Paulo: Paz e Terra, 1999.

Redes de Indignação e Esperança. Movimentos Sociais na era da Internet. Rio de Janeiro, Zahar, 2013.

DOMINICÉ, P. A formação de adultos confrontada pelo imperativo biográfico. Educação e Pesquisa, São Paulo, v.32, n.2, p. 345-357, maio/ago. 2006.

DI FELICE, M. Ser redes: o formismo digital dos movimentos net-ativistas. Revista Matrizes, n. 2, jul./dez. 2013, p. 49-71

GROSFOGUEL, R. A estrutura do conhecimento nas universidades ocidentalizadas: racismo/sexismo epistêmico e os quatro genocídios/epistemicídios do longo século XVI. Revista Sociedade e Estado. Vol. 31, n. 1, Janeiro/Abril, 2016.

HARAWAY, D. Manifesto ciborgue: Ciência, tecnologia e feminismo-socialista no final do século XX. In: TADEU, T.; HUNZRU, H.; HARAWAY, D. (org.) Antropologia do ciborgue: as vertigens do pós-humano. 2. ed. Belo Horizonte: Autêntica Editora, 2009.

HOOKS, B. Mulheres negras: moldando a teoria feminista. Revista Brasileira de Ciência Política, n.16. Brasília, janeiro - abril de 2015, p. 193-210.

2017.

Ensinando a transgredir: A educação como prática da liberdade. São Paulo: Ed. WMF Martins Fontes,

JUNGBLUT, A. L. Práticas ciberativistas, agência social e ciberacontecimentos. Vivência: Revista de Antropologia. n. 45, p. 13-22, 2015.

LEMOS, A. Cibercultura: tecnologia e vida social na cultura contemporânea. Porto Alegre: Sulina, 2010.

LÈVY, P. Cibercultura. Rio de Janeiro: 34, 1999.

MARTINS, B. Autoria em rede: os novos processos autorais através das redes eletrônicas. $1^{\text {a }}$ ed. Rio de Janeiro: Mauad, 2014.

OLIVEIRA, L. F.; CANDAU, V. M. F. Pedagogia decolonial e educação antirracista e intercultural no Brasil. Educação em Revista. Belo Horizonte, v. 26, n. 1, p. 15-40, abr. 2010.

PIMENTA, S. G. Formação de professores - saberes da docência e identidade do professor. Revista Nuances, v. 3, 1997.

QUIJANO, A. Colonialidad del poder, eurocentrismo y América Latina. In: LANDER, E. (Org.). La colonialidad del saber: eurocentrismo y ciencias sociales. Perspectivas Latinoamericanas. Buenos Aires: Clacso, 2005. p. $227-277$.

RÜDIGER, F. Introdução às teorias da cibercultura: perspectivas do pensamento tecnológico contemporâneo. Porto Alegre: Sulina, 2003.

ZUBOFF, S. The age of surveillance capitalism. The fight for human future at the new frontier of power. New York. Public Affairs, 2019.

WALSH, C. Interculturalidad crítica y pedagogía de-colonial: apuestas (des)de el insurgir, re-existir y re-vivir. Quito, Universidad Andina Simón Bolívar sede Ecuador, 2008. Disponível em: <https://www.maxwell.vrac.pucrio.br/13582/13582.PDFXXvmi=di9ixOJob3xjBuscxZPZhgoEsplxlhlzBvSzkDZvGWP>. Acesso em 21 mai. 2019. 


\section{RESUMO}

Este trabalho demonstra como o ativismo em rede de mulheres negras vlogueiras no YouTube articula processos associados a uma pedagogia decolonial. A pesquisa qualitativa abrangeu o estudo de três canais de mulheres negras no YouTube, onde foram coletados dados sobre 32 vídeos publicados e sobre as demais interações que ocorreram entre elas e seguidores dos canais. A coleta de dados foi realizada através da realização de entrevistas semiestruturadas com as mesmas e da observação das atividades ocorridas nos canais. Esse ativismo produziu aprendizagens para elas e para os seguidores dos canais na perspectiva de uma pedagogia decolonial, que ocorreu particularmente ao questionarem e debaterem sobre os padrões estéticos de beleza construídos na base de uma sociedade racista e excludente.

Palavras-chaves: Ativismo em rede, Pedagogia Decolonial, Mulheres negras

\section{ACTIVISMO EN RED Y PEDAGOGÍA DECOLONIAL ARTICULADOS POR MUJERES NEGRAS EN YOUTUBE}

\section{RESUMEN}

Este trabajo demuestra cómo el activismo en red de mujeres negras vlogueras, en el YouTube, articula procesos asociados a una pedagogía de-colonial. La investigación cualitativa abarcó el estudio de tres canales de mujeres negras del YouTube, donde fueron coleccionados datos sobre 32 videos publicados y sobre las demás interacciones que ocurrieron entre ellas y seguidores de los canales. La recolección de los datos fue realizada a través de la realización de entrevistas semiestructuradas con las mismas y de la observación de las actividades ocurridas en los canales. Este activismo produjo aprendizajes para ellas y para los seguidores de los canales en la perspectiva de una pedagogía de-colonial, que ocurrió particularmente al cuestionar y debatir sobre los patrones estéticos de la belleza construyéndose sobre la base de una sociedad racista y excluyente.

Palabras claves: Activismo en red, Pedagogía Decolonial, Mujeres negras

\section{NETWORK ACTIVISM AND DECOLONIAL PEDAGOGY ARTICULATED BY BLACK WOMEN ON YOUTUBE}

\section{ABSTRACT}

This article demonstrates how the networked activism of black female vloggers on YouTube articulates processes associated with a decolonial pedagogy. The qualitative research included the study of three channels of black women on YouTube, where data were collected on 32 videos published and on the other interactions that occurred in these channels between them and channel followers. Data collection was carried out by observing the activities that took place in the channels. This activism produced learning for them and for the followers of the channels in the perspective of a decolonial pedagogy, which occurred particularly when they questioned and debated about the aesthetic standards of beauty built on a racist and exclusionary society.

Keywords: Networked Activism, Decolonial Pedagogy, Black Women

Submetido em Agosto de 2019

Aprovado em Novembro de 2019 